\title{
Os cadernos de desenho de Anita Malfatti. Um diário de criação à revelia e índices de um projeto pictórico em Paris
}

\author{
[ Anita Malfatti's sketchbooks. A creative diary without her \\ explicit intention and indices of a pictorial project in Paris
}

\section{Roberta Paredes Valin ${ }^{\mathrm{I}}$}

A trajetória artística de Anita Malfatti (I889-I964) foi desenhada a partir de dicotomias que fizeram dela uma das mais complexas e interessantes da história da arte brasileira. Entre questões práticas e espirituais, vivendo momentos de conflito e de superação, com dificuldades financeiras e inquietudes sobre sua arte, transitando entre a vanguarda e a tradição e tensionada entre o nacional e o universal, Anita sofreu duros questionamentos no ambiente artístico paulista da primeira metade do século XX.

A documentação reunida por Anita em seu acervo pessoal ao longo do tempo possibilita compreender esse movimento sinuoso, contraditório e instigante que traduz a sua vida e, sobretudo, sua criação. Entre esses documentos, a grande maioria deles sob a guarda do Instituto de Estudos Brasileiros da Universidade de São Paulo (IEB-USP), destacam-se as cartas que recebeu de Mário de Andrade, vários manuscritos de conferências e cursos que ministrou, fotografias, alguns cadernos contendo recortes de jornais e, em especial, dezessete cadernos de desenho ${ }^{2}$.

Os cadernos de desenho da artista merecem especial atenção porque revelam um movimento assíncrono de elaboração e reelaboração de um pensamento em processo, às voltas com a criação, permitindo-nos uma aproximação do seu projeto estético. São também documentos que legitimam historicamente sua trajetória artística, na medida em que os desenhos e as breves anotações ali contidas formam uma espécie de memória fragmentada que concede peças importantes para a reconstituição do seu itinerário de criação (figura I).

DoI: http://dx.doi.org/Io.II606/issn.23I6-90IX.voi63Ip242-257

I Mestre pelo Instituto de Estudos Brasileiros da Universidade de São Paulo (IEB-USP), com pesquisa intitulada Cadernos-diários de Anita Malfatti - uma trajetória desenhada em Paris, sob orientação de Ana Paula Cavalcanti Simioni, docente do IEB-USP.

2 Grande parte da documentação citada encontra-se salvaguardada pelo IEB-USP desde I989, quando, por intermédio da pesquisadora e professora Marta Rossetti Batista, a família de Anita Malfatti doou seu acervo pessoal ao referido Instituto. $\mathrm{O}$ acervo encontra-se presente em três setores do instituto: Arquivo, Biblioteca e Coleção de Artes Visuais, ficando os cadernos de desenhos da artista neste último setor. 


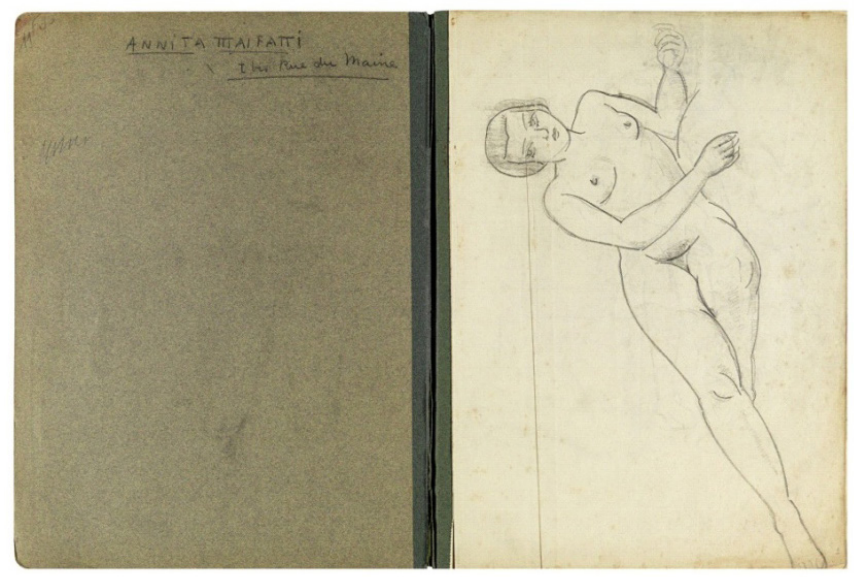

Caderno CAV-AM-CD-0004 - folhas 00v \& $01 \mathrm{f}$.

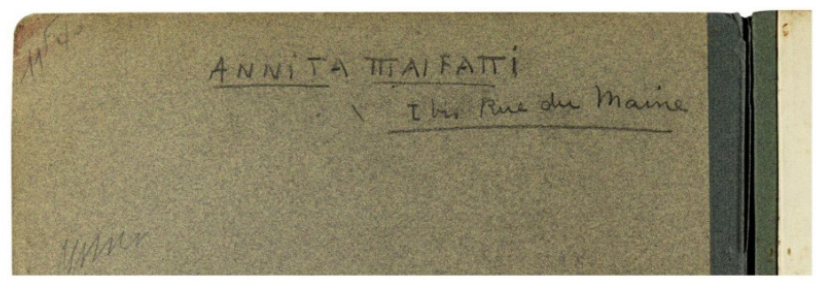

Detalhe do caderno CAV-AM-CD-0004 - folha 00v\&00f.

Figura I: CAV-AM-CD-0004_oIf. MALFATTI, Anita Catarina. Caderneta de desenho Carnet Croquis, I923/25C - caderno, 34,9 cm × 24,9 cm. Nu reclinado. Coleção Anita Malfatti. Coleção de Artes Visuais do Instituto de Estudos Brasileiros da USP

Do conjunto de dezessete cadernos, nove deles remetem ao período em que a artista esteve em Paris, como bolsista do Pensionato Artístico de São Paulo ${ }^{3}$, entre os anos de I923 e I928 - sua última viagem de estudos ao exterior. Enquanto bolsista, cabia a ela - de forma um tanto flexível, importante ressaltar - cumprir com o que normatizava tal programa, o que a levou a elaborar desenhos de modelo vivo, pintar academias e realizar esboços sobre assunto histórico, bíblico ou mitológico, além de pintar cópias de obras célebres. Como trabalho final, também lhe cabia elaborar uma tela com base nesses mesmos assuntos ${ }^{4}$. Tais exigências levaram Anita Malfatti a

3 Os nove cadernos seguem a catalogação feita pela Coleção de Artes Visuais do IEB-USP, com os seguintes números de tombo: CAV-AM-CD-ooo2, CAV-AM-CD-o003, CAV-AM-CD-0004, CAV-AM-CD-0005, CAV-AM-CD-0006, CAV-AM-CD-0007, CAV-AM-CD-ooo8, CAV-AM-CD-ooIo e CAV-AM-CD-ooI7.

4 Ver CAMARGOS, Márcia. Entre a vanguarda e a tradição. Os artistas brasileiros na Europa (I9I2-I930). São Paulo: Alameda, 20II. 
frequentar academias de arte, em especial cursos livres de croqui, a fim de exercitar o modelo vivo, como a Académie de la Grande Chaumière e a Académie Ranson ${ }^{5}$ (figura 2), e realizar alguns esboços para futuros projetos, executados ou não.

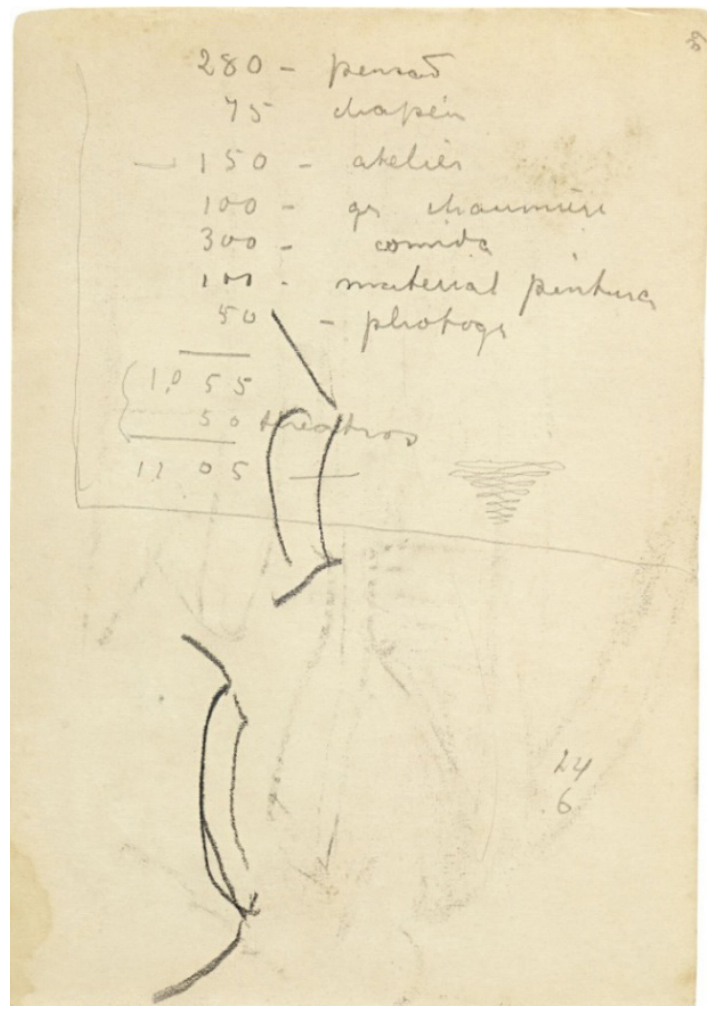

Figura 2: CAV-AM-CD-0003_39f. MALFATTI, Anita Catarina. Caderneta de desenho II, Contas, I9I8/24C - caderno (desenho), II,3 cm × I6,4 cm. Coleção Anita Malfatti. Coleção de Artes Visuais do Instituto de Estudos Brasileiros da USP

Nessa viagem de estudos, os cadernos de desenho, por serem suportes, espaços de criação de fácil transporte e flexíveis, capazes de abarcar informações de variada natureza e diferentes técnicas escriturais/pictóricas, carregam muitos índices da criação e da formação artística de Anita Malfatti. Acolhem breves anotações - como as listas de pagamentos, onde consta a referência à Académie de la Grande Chaumière (figura 3) -, os muitos nus femininos e esboços para pinturas, a exemplo daqueles

5 BATISTA, Marta R. Anita Malfatti no tempo e no espaço. Biografia e estudo da obra. São Paulo: Editora 34, 2006. 
ligados à criação das telas La rentrée e Mulher do Pará (figuras 4 e 5), escritos em sua maioria a grafite, alguns poucos em cores ${ }^{6}$.

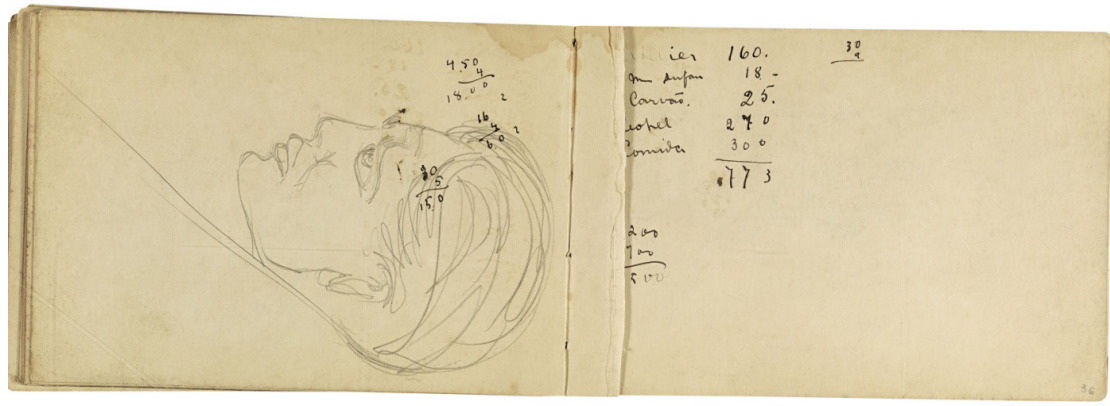

Figura 3: CAV-AM-CD-0003. MALFATTI, Anita Catarina. Caderneta de desenho II, I9I8/24C - caderno (desenho), II, $3 \mathrm{~cm} \times I 6,4 \mathrm{~cm}$. Cabeça de perfil e Contas com bico de pena "atelier I60/M Sufan I8/Carvão 25/ Hotel 270/Comida 300...". Coleção Anita Malfatti. Coleção de Artes Visuais do Instituto de Estudos Brasileiros da USP

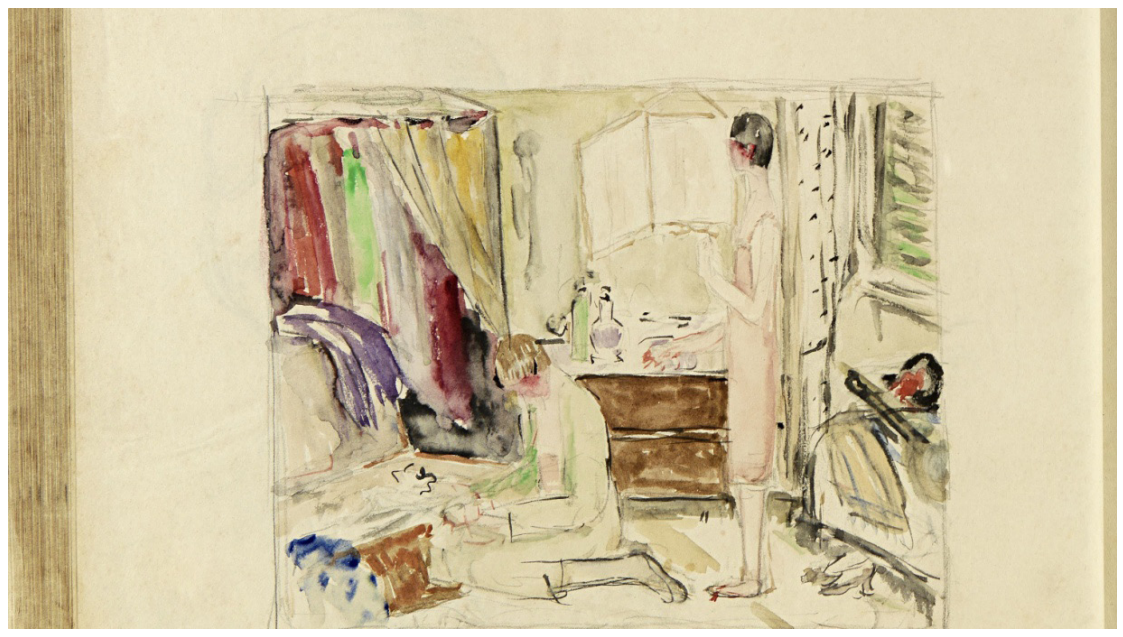

Figura 4: CAV-AM-CD-0003_59v. MALFATTI, Anita Catarina. Caderneta de desenho II, I9I8/24C - caderno (desenho), II,3 cm × I6,4 cm. Estudo para "La Rentrée". Coleção Anita Malfatti. Coleção de Artes Visuais do Instituto de Estudos Brasileiros da USP

6 Ver: ELUF, Lygia (org.). Anita Malfatti - Coleção Cadernos de Desenho. Campinas: Editora Unicamp/Imprensa Oficial do Estado de São Paulo, 20II. Marta Rossetti Batista, em sua biografia de Anita Malfatti, divulgou alguns desenhos dos cadernos da pintora, sem analisá-los detidamente. Ana Paula Cavalcanti Simioni e Ana Paula F. C. Lima, na Coleção Cadernos de Desenho, organizada por Lygia Eluf, cumpriram uma análise mais aprofundada dessa documentação, especialmente em relação ao estilo, ao nu e aos esboços de obras que Anita elaborou em Paris. Os apontamentos críticos das autoras foram de grande importância para os direcionamentos iniciais da minha pesquisa de mestrado. 


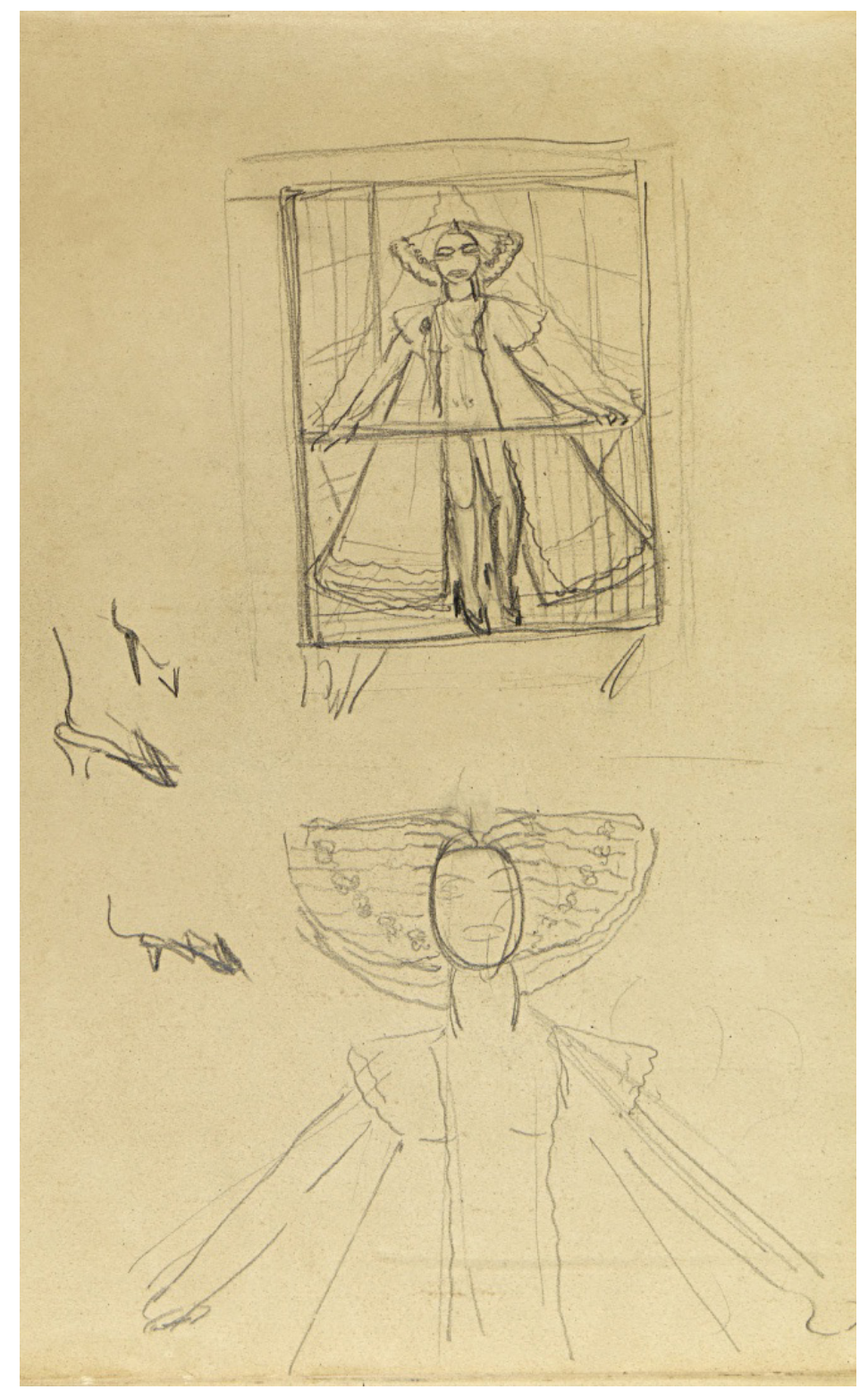

Figura 5: CAV-AM-CD-ooI7_32v. MALFATTI, Anita Catarina. Caderneta de desenho II, I9I8/24C - caderno (desenho), II,3 cm × I6,4 cm. Estudos para "Mulher do Pará". Coleção Anita Malfatti. Coleção de Artes Visuais do Instituto de Estudos Brasileiros da USP

Os cadernos de desenho da artista podem ser interpretados como cadernos-diários de criação. Essa aproximação, distante da definição convencional de um diário aquele que contém escrita confessional e confidencial e certos padrões formais de organização -, deve ser vista de forma relativizada. Seus cadernos são, nesse contexto, diários à revelia, fora dos padrões formais, especialmente por não terem quaisquer 
vestígios de datas e não conterem uma narrativa linear. Aproximam-se da ideia de “diário" porque são espaços reservados, íntimos, em que a artista refletiu sobre si e sobre a sua obra, marcas de trabalho que desvelam o percurso de uma poética que se inicia no desenho.

Se nos cadernos-diários de criação de Anita o desenho se sobrepõe à escrita e estrutura a narrativa (da criação) ali presente, ele (o desenho), em especial os nus, acaba por revelar características importantes da escrita gráfica da artista, especialmente quando comparamos com seus desenhos de tendência expressionista da década de I9Io. Em Paris, Anita mostra maior interesse pelo nu feminino nas aulas de modelo vivo, diferentemente da prevalência do nu masculino em sua estadia nos Estados Unidos. Essa diferença, no entanto, não se restringe somente às questões de gênero, imprime também uma característica de estilo para seu desenho. Nos nus da década de I920, Malfatti deixa de lado a representação do corpo humano moldada pela valorização da musculatura, em especial a masculina, bem definida e marcada pelo traço forte feito a carvão, que exalta a expressividade do corpo, e passa a trabalhar com um traço leve, limpo, sintético, com poucos ou ausentes sombreados, cuja economia e a precisão dos traços definiram, quase unicamente, corpos femininos sensuais, naquela oportunidade7 (figura 6).

Um olhar mais atento sobre esses cadernos ainda destaca outro dado sobre a prática do desenho por Anita: a presença de um método. As marcas de lápis, algumas mais fracas ou apagadas, revelam seu método peculiar de desenhar, o qual consiste, primeiramente, em cuidar de esboçar de forma rápida o corpo da modelo para, em seguida, defini-lo com uma linha precisa e contínua que aproxima seu traçado dos desenhos clássicos, segundo Winckelmann, portadores de uma nobre simplicidade e uma grandeza serena ${ }^{8}$.

Tendo em vista essas características, seus desenhos seguem as transformações pelas quais sua produção pictórica passou. A pintura de tendência expressionista na década de I9Io encontra correspondência em seus desenhos do mesmo período. Em relação às pinturas vincadas por "valores artísticos tradicionais e convencionais e

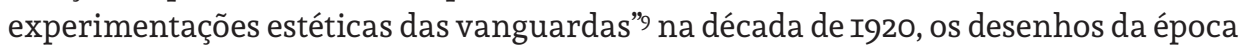
seguem o mesmo estilo. Pode-se afirmar, assim, que Malfatti buscou, por caminhos tortuosos, uma coerência em sua poética.

7 Sobre os desenhos de Anita Malfatti, em especial aqueles que remetem à sua fase francesa, ver BATISTA, Marta R. Op. cit., p. 324-329, e MALFATTI, Anita. Op. cit.

8 CHIARELLI, Tadeu. Anita Malfatti expressionista e clássica. In: Anita Malfatti: desenhos dos anos Io e 20. São Paulo: Galeria Sinduscon, I995.

9 Idem. 


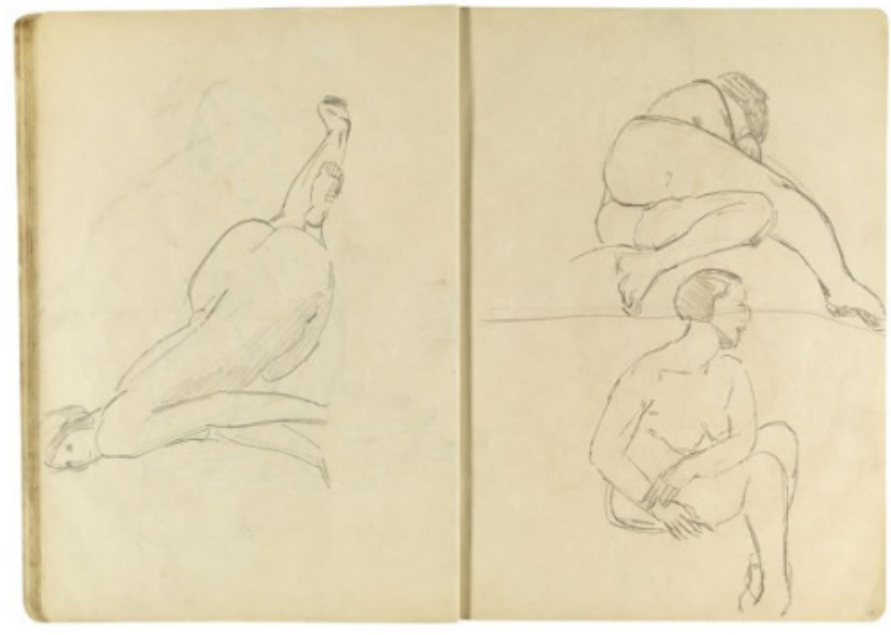

CAV-AM-CD-0004. Nu sentado no chão com tronco inclinado e Nu deitado com pés em primeiro plano e nu sentado com mãos na perna

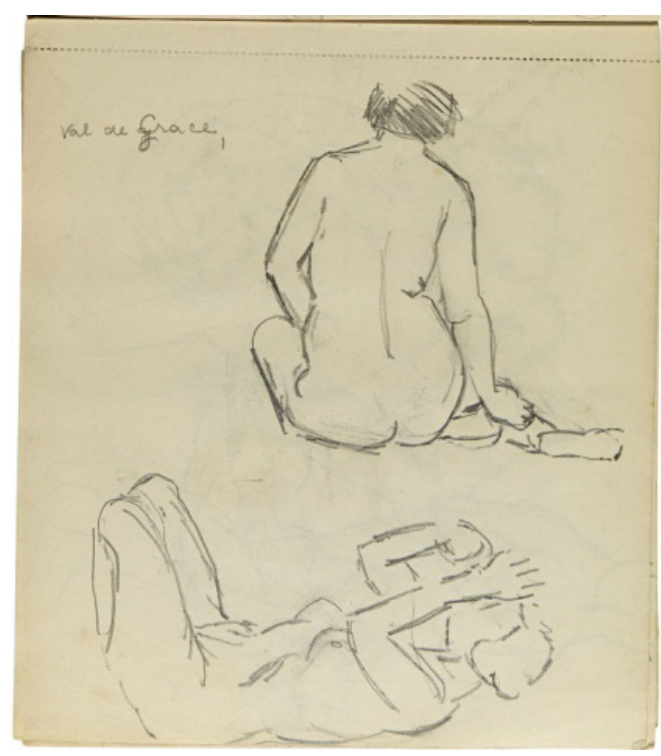

CAV-AM-CD-0006_I6v. Nu sentado de costas e esboço de nu ajoelhado 


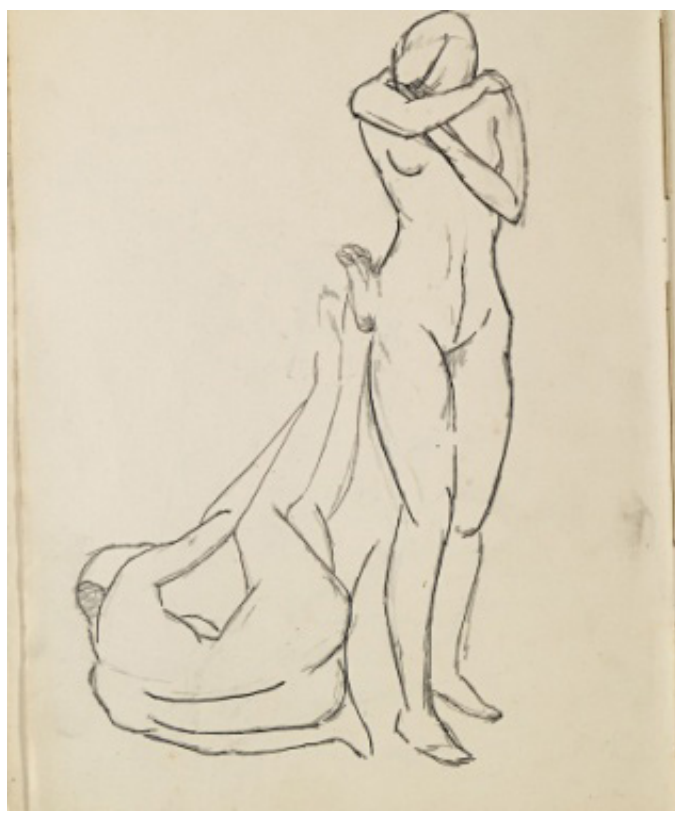

CAV-AM-CD-0007_3v. Nu de costas sentado e nu em pé com mãos cobrindo o rosto

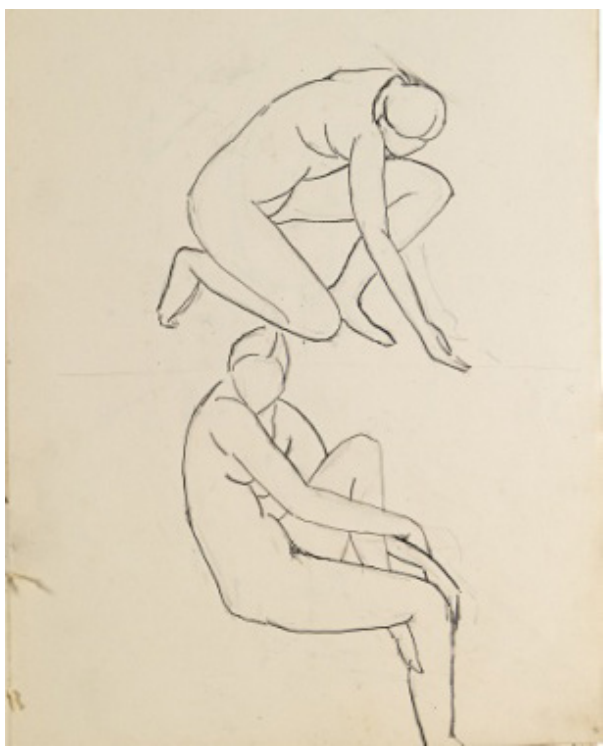

CAV-AM-CD-0007_4f. Nu agachado e inclinado para o chão e $n u$ sentado com mãos envolvendo perna esquerda levantada 


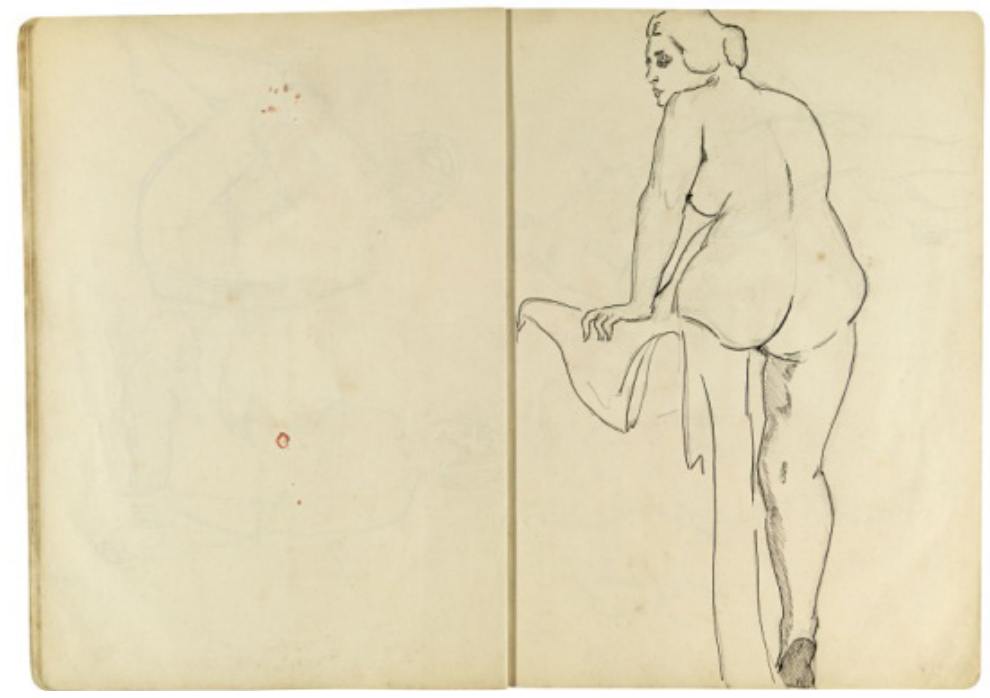

CAV-AM-CD-0004_I4f. Nu de costas, sentado em apoio alto coberto

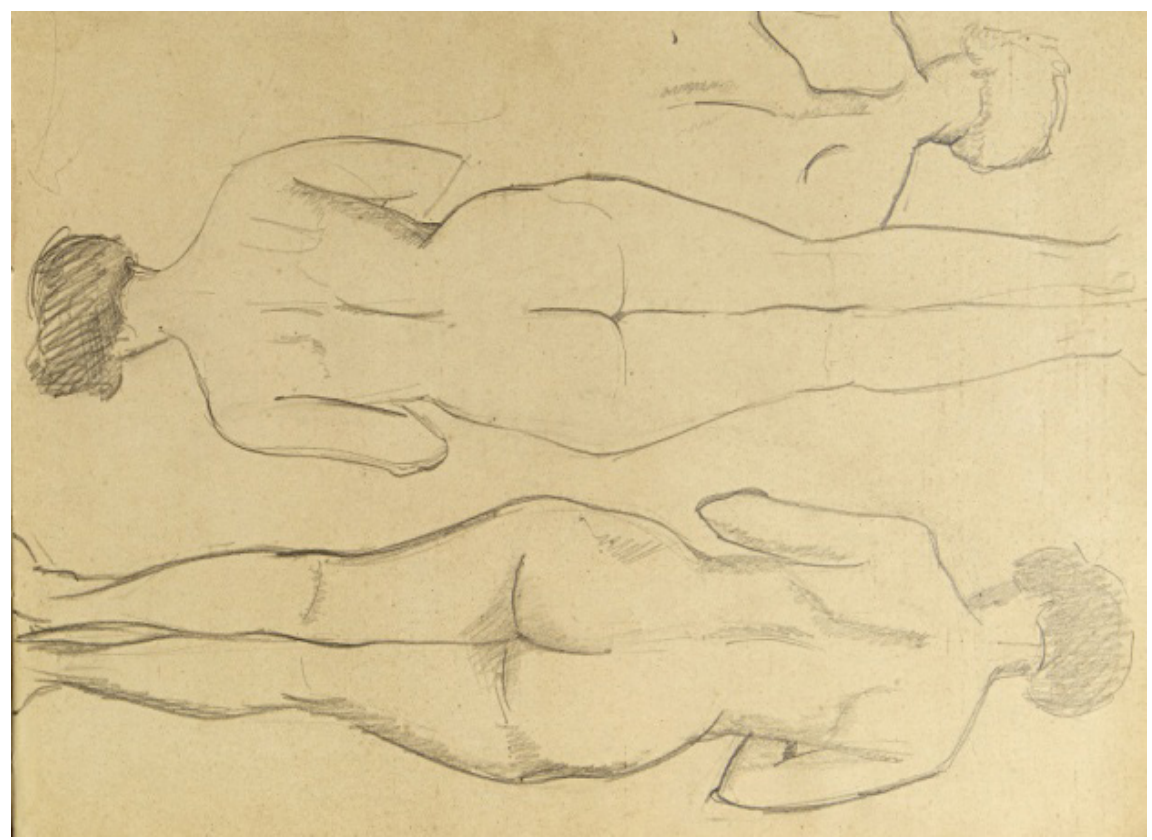

CAV-AM-CD-ooI7_2of. Nus de costas e esboço de cabeça 


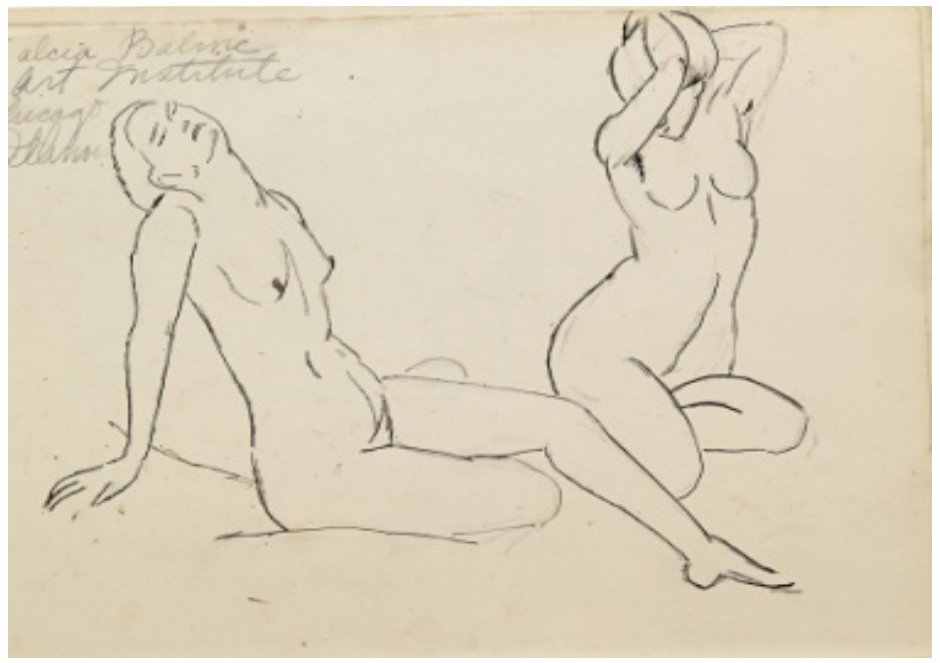

CAV-AM-CD-0007_o2v. Nu sentado olhando para cima (esquerda) e nu agachado com mãos na cabeça (direita)

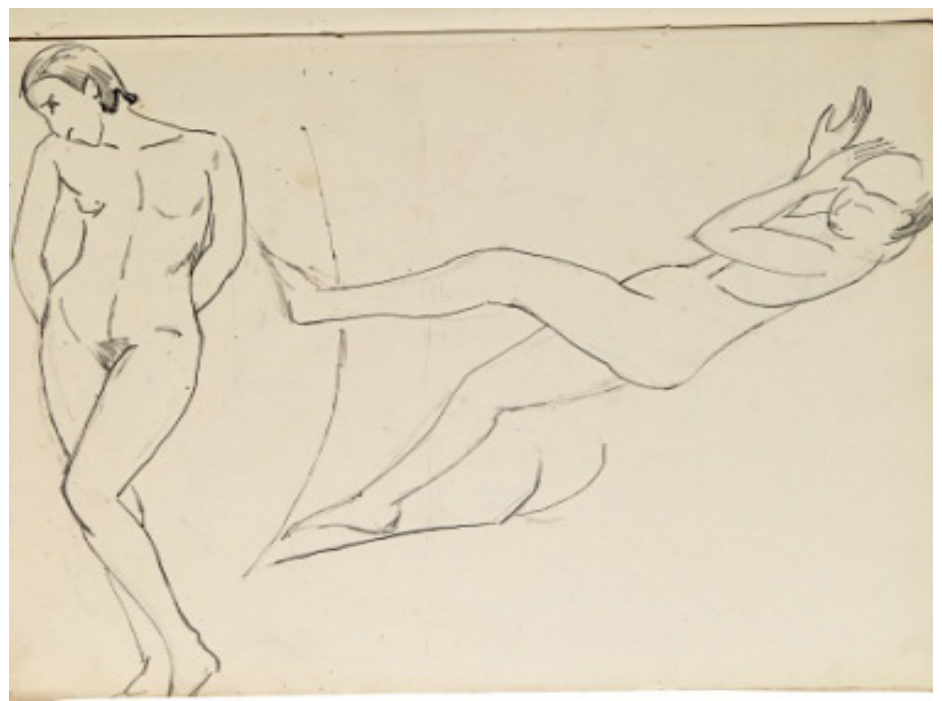

CAV-AM-CD-0007_03f. Nu andando e nu com mãos nas costas

Figura 6: MALFATTI, Anita Catarina. Caderneta de desenho II, I9I8/24C - caderno (desenho), II,3 cm x I6,4 cm. Coleção Anita Malfatti. Coleção de Artes Visuais do Instituto de Estudos Brasileiros da USP

A definição de “cadernos-diários” de criação ganha ainda mais sustentação quando observamos um conjunto de oito esboços feitos para uma única tela, espalhados por 
alguns dos cadernos. Trata-se dos desenhos preparatórios para a tela Ressurreição de Lázaro ${ }^{\mathrm{IO}}$, vista como sua obra-tese para o Pensionato, conforme apontaram as pesquisas de Marta Rossetti Batista ${ }^{\text {II }}$. Esse conjunto de esboços (figuras 7 e 8) foi uma peça fundamental para compreender a obra como obra-tese e, portanto, como o seu grande e importante projeto pictórico na ocasião em que esteve em $\mathrm{Paris}^{\mathrm{I2}}$. Um projeto que se transformou em uma espécie de símbolo de uma fase cheia de percalços e superações, tanto na vida pessoal quanto na criação da artista, representativa de um momento de "ressurreição" vivido por ela - recuperando seu modo de pensar em carta a Mário de Andrade ${ }^{\mathrm{I3}}$ - após passar por problemas financeiros, ter a saudade como companheira e vivenciar angústias e aflições nas tentativas de encontrar um caminho para sua pintura.

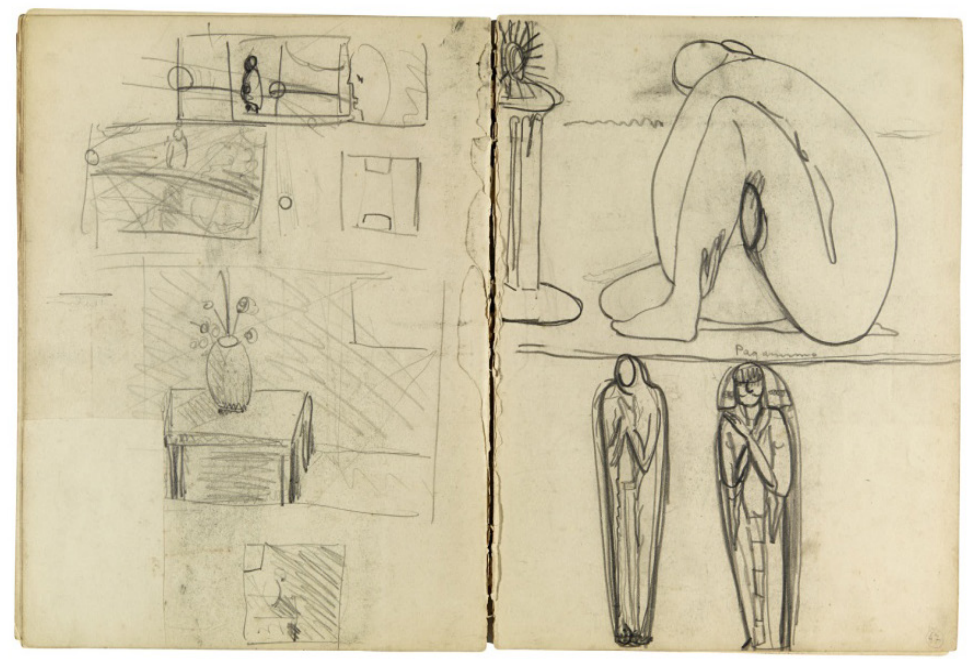

\section{CAV-AM-CD-0002_47f. Composição com nu sentado e dois esboços de múmia}

Io Ressurreição de Lázaro, I928. Óleo sobre tela, Museu de Arte Sacra de São Paulo.

II BATISTA, Marta R. Op. cit.

I2 O entendimento de que a obra Ressurreição de Lázaro foi o grande projeto pictórico da artista em Paris, exposto no trabalho Cadernos-diários de Anita Malfatti - uma trajetória desenhada em Paris, foi embasado nas pesquisas de Marta Rossetti Batista sobre a vida e a obra de Anita. De acordo com suas investigações, Ressurreição de Lázaro foi a obra com a qual a artista cumpriu o seu compromisso com o Pensionato Artístico de São Paulo, sendo chamada pela pesquisadora de obra-tese. O contato com a documentação pessoal da artista permite a reconstrução do itinerário de criação da obra, levando à comprovação de que Anita, desde o primeiro ano em que esteve em Paris, já, de alguma forma, dedicava-se a esse projeto.

I3 Carta a Mário de Andrade, em 8 de abril de I925. Nela, Anita Malfatti questiona o amigo: "Tu que és tão Cristão não crês na vida? Deve-se compreender a vida e aniquilar a morte. Leia todo o evangelho de S. João o discípulo amado. Ele te curará perfeitamente como me curou. $\mathrm{O}$ amor divino destrói todo o mal inclusive toda e qualquer moléstia” (Série Correspondência, Arquivo Mário de Andrade, IEB-USP). 


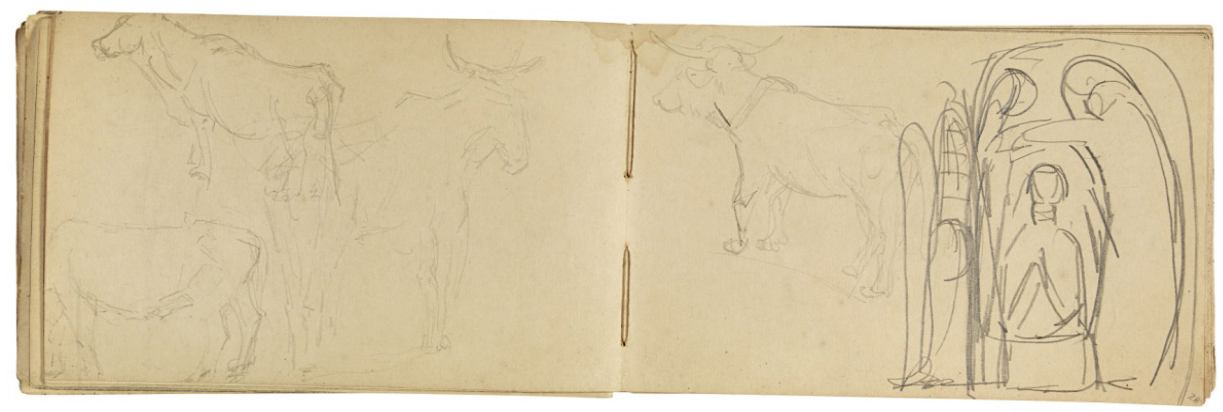

CAV-AM-CD-0003_28f. Esboço: boi e estudo para Ressurreição de Lázaro

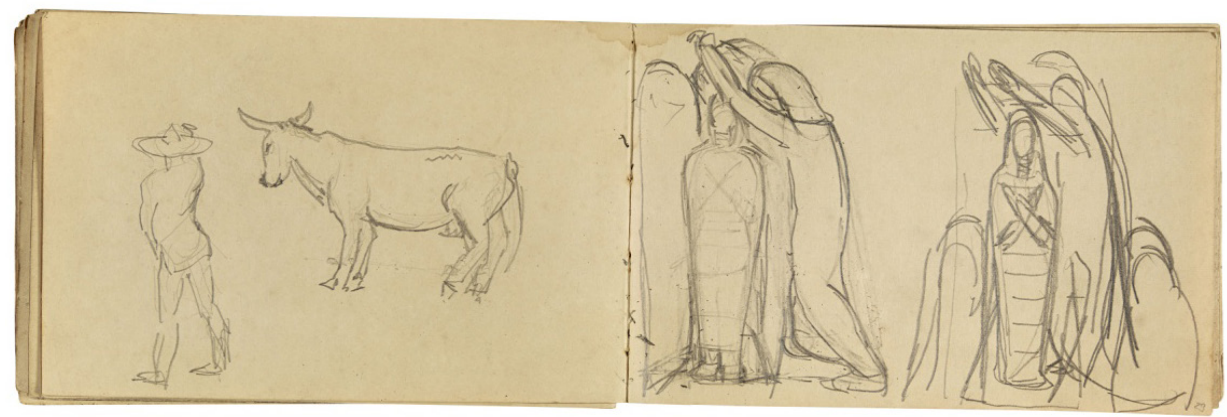

CAV-AM-CD-0003_29f. Esboço: boi e estudo para Ressurreição de Lázaro

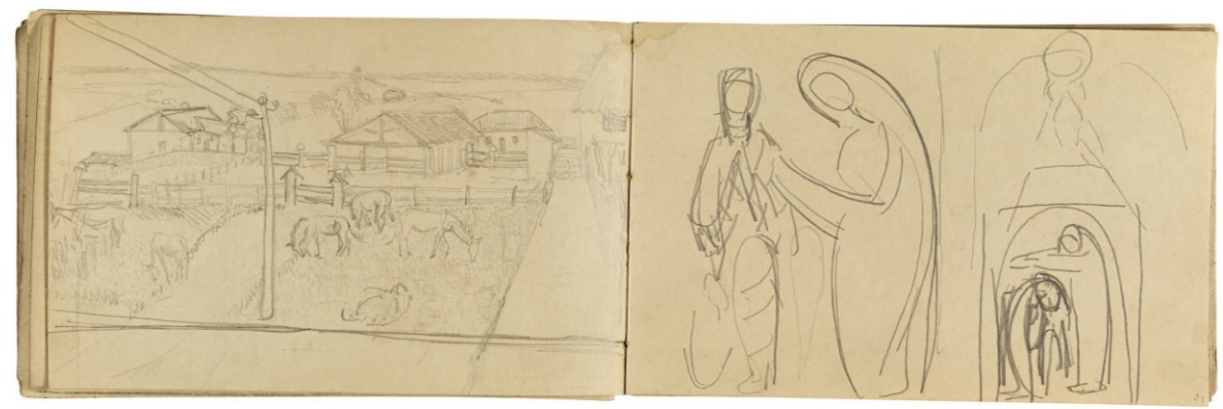

CAV-AM-CD-0003_27f. Estudos de composição para Ressurreição de Lázaro 


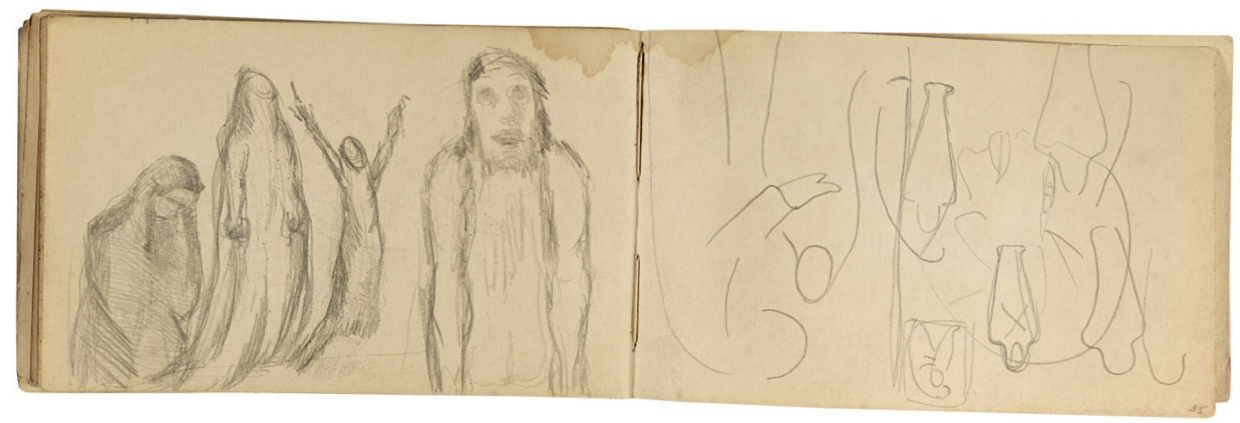

CAV-AM-CD-0003_35f. Esboço: figuras com manto e silhuetas

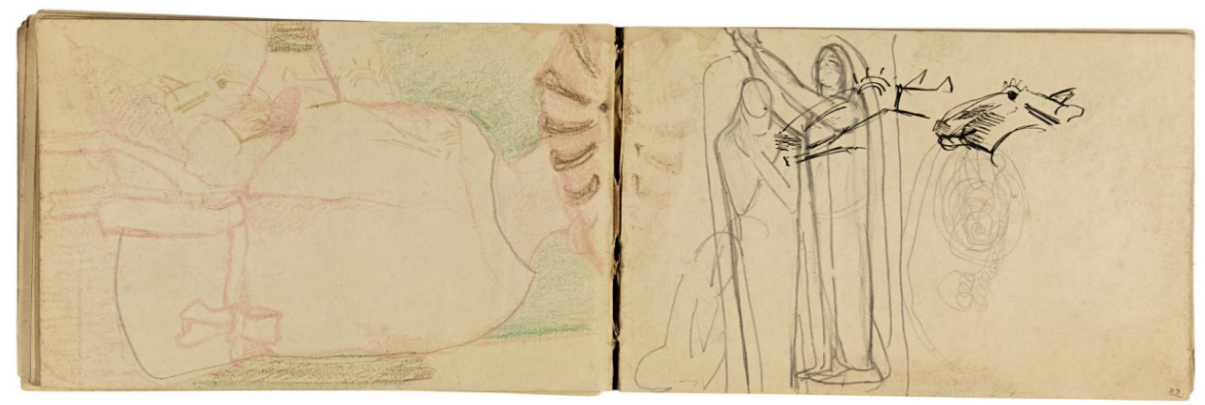

CAV-AM-CD-0003_32f. Estudo: Lázaro e Cristo, e cabeça de animal

Figura 7: MALFATTI, Anita Catarina. Caderneta de desenho II, I9I8/24C - caderno (desenho), II,3 cm x I6,4 cm. Coleção Anita Malfatti. Coleção de Artes Visuais do Instituto de Estudos Brasileiros da USP 


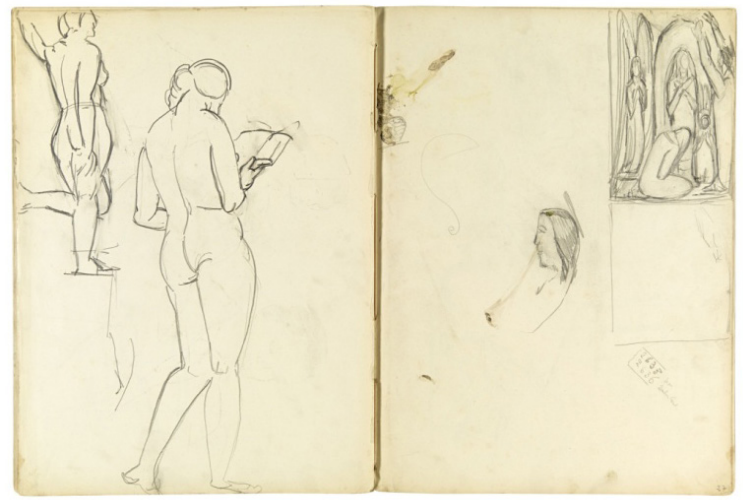

CAV-AM-CD-0005_27f. Esboço para Ressurreição de Lázaro (c.s.d.) e cabeça de Cristo (centro).

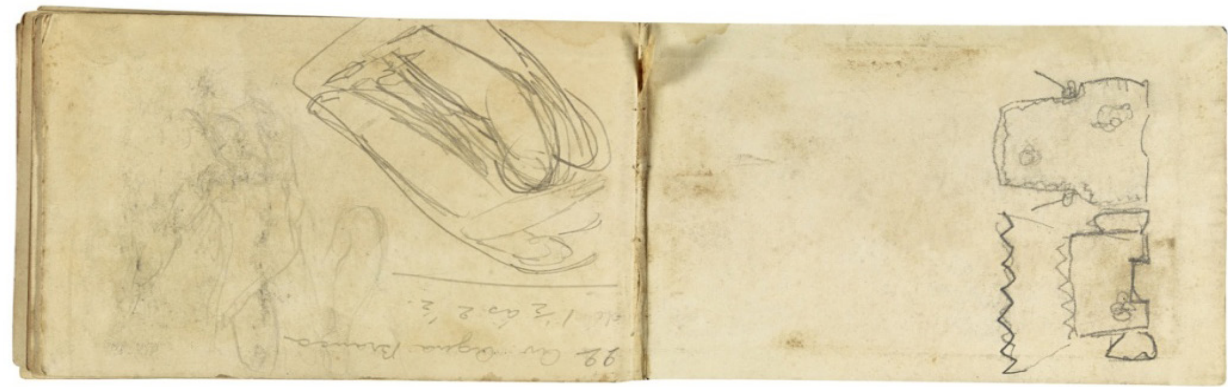

CAV-AM-CD-0003_39v. Esboço: figuras humanas.

Figura 8: MALFATTI, Anita Catarina. Caderneta de desenho II, I9I8/24C - caderno (desenho), II,3 cm x I6,4 cm. Coleção Anita Malfatti. Coleção de Artes Visuais do Instituto de Estudos Brasileiros da USP

Compreender Ressurreição de Lázaro requer não apenas a observação dos esboços encontrados nos cadernos, como também de outras fontes, como correspondência e fotografias ${ }^{\mathrm{I}}$. Analisando especificamente os cadernos de desenho, a série de oito esboços revela de forma direta o movimento criador por trás da obra acabada, o mesmo movimento que nos aproxima da obra e, sobretudo, das intenções da artista a partir de suas experimentações, inquietações, escolhas e mudanças de caminho.

I4 Na pesquisa de mestrado mencionada foram articuladas as correspondências de Malfatti com Mário de Andrade e Freitas Valle, patrono do Pensionato Artístico de São Paulo, além de fotografias de obras de Giotto e Fra Angelico, e também da tela estudo e da primeira versão da obra Ressurreição de Lázaro, a fim de reconstruir as etapas da criação que nos aproximam da gênese da obra. 
Nesses esboços notam-se três questões formais a serem desenvolvidas e resolvidas: a figura de Lázaro, a de Cristo e a própria composição.

Na composição que retrata o ponto mais nevrálgico do episódio bíblico - quando Cristo vai ao encontro de Lázaro e o ressuscita dos mortos - é possível perceber que para a figura de Lázaro Anita buscou, através de muitos esboços, definir a forma ideal, uma espécie de sarcófago, e a sua posição mais adequada na composição, questão que parece ter resolvido já nos esboços: mãos em cruz sobre o tronco, o corpo coberto por faixas, assim como eram embalsamados os mortos na época. No que tange à figura de Cristo, a preocupação da artista volta-se para sua posição diante de Lázaro: com um ou dois braços ao alto, elevados ao céu, apontando ou não o anjo na parte superior da tela - conforme a versão final e a tela estudo, respectivamente. Quanto à composição, os esboços, quando analisados junto à tela, revelam que Anita ainda não estava certa em relação ao eixo principal da figuração, principalmente porque a inserção do anjo na parte superior (presente na versão final) ainda não fazia parte da composição. Com essas tentativas, Malfatti buscava o bom equilíbrio entre as figuras e a relação precisa entre os elementos, a fim de criar um conjunto harmonioso. No entanto, só conseguiu resolver todas essas questões deixadas em aberto nos esboços após o retorno de uma breve temporada na Itália.

Por meio dos esboços fica evidente que a composição já se encontrava quase pronta por volta de I925 (figura 8 - imagem do lado direito). No entanto, a tradição da pintura italiana do Trecento e Quattrocento italiano, através das obras La Risurrezione di Lazzaro, de Fra Giovanni Angelico, e Resurrezione di Lazzaro, de Giotto di Bondonne, foi fundamental para Malfatti finalizar a obra. Mesmo estando sob o crivo do Pensionato, fica claro que ao entrar em contato com a iconografia italiana dos períodos citados, em especial a religiosa, como a Ressurreição de Lázaro, a artista se alinhava a uma tendência artística que alcançava repercussão na época, o Retorno à Ordem - uma tendência que valorizava o resgate do passado combinado às conquistas artísticas modernas já alcançadas pelas vanguardas, muito em voga na Escola de Paris ${ }^{15}$. Não só suas pinturas, mas também seus desenhos, estão em acordo com esse discurso.

Sob essa perspectiva, Anita dialoga não só com a Arte Primitiva pré-renascentista - a notar pela simplificação dos objetos representados a partir da estilização das figuras que confere rigidez aos seus corpos - como também com a arte moderna. O diálogo com a vanguarda é evidente quando se observa a escolha da artista em dimensionar em grande escala os personagens e inseri-los em um mesmo plano, aparentemente todos dividindo o mesmo espaço estreito da composição (fugindo, assim, de certas convenções naturalistas ao distanciar-se da rigidez do tridimensional), e pela paleta de cores adotada, com tons mais suaves, mesmo quando

I5 Ver BATISTA, Marta R. Op. cit. Sobre a Escola de Paris e Anita Malfatti, ver BATISTA, Marta R. Os artistas brasileiros na Escola de Paris. Anos 20. São Paulo: Editora 34, 20I2; PINTO, S. M. de Carvalho. A controversa pintura de Anita Malfatti. Tese (Doutorado). São Paulo: Universidade de São Paulo, 2007; CARDOSO, Renata Gomes. Modernismo e tradição: a produção de Anita Malfatti nos anos de I920. Tese (Doutorado). Campinas: Universidade Estadual de Campinas, $20 \mathrm{I2}$. 
se apropriou de certos padrões de cores conferidos à tradição, como as das roupas de Cristo e Maria. A artista finalizou a obra em I928.

Os cadernos-diários de criação de Anita Malfatti apresentam muitas camadas para análise. Tornam tangível o que é intangível, desvelam os complexos bastidores da criação. Colaboram para que parte expressiva de sua obra se desvencilhe da névoa do desconhecido - como a produção de temática religiosa, as paisagens e festanças do interior e os retratos - e ganhe espaço nas discussões que têm como escopo a arte brasileira do início do século XX, suscitando releituras do modernismo brasileiro.

SOBRE A AUTORA

Mestre pelo Instituto de Estudos Brasileiros da Universidade de São Paulo (IEB-USP), com pesquisa intitulada Cadernos-diários de Anita Malfatti - uma trajetória desenhada em Paris, sob orientação de Ana Paula Cavalcanti Simioni, docente do IEB-USP.

\section{REFERÊNCIAS BIBLIOGRÁFICAS}

BATISTA, Marta R. Anita Malfatti no tempo e no espaço. Biografia e estudo da obra. São Paulo: Editora 34, 2006.

. Os artistas brasileiros na Escola de Paris. Anos 20. São Paulo: Editora 34, 2012.

CAMARGOS, Márcia. Entre a vanguarda e a tradição. Os artistas brasileiros na Europa (I9I2-I930). São Paulo: Alameda, $20 I I$.

CARDOSO, Renata Gomes. Modernismo e tradição: a produção de Anita Malfatti nos anos de I920. Tese (Doutorado). Campinas: Universidade Estadual de Campinas, 20I2. CHIARELLI, Tadeu. Anita Malfatti expressionista e clássica. In: Anita Malfatti: desenhos dos anos Io e 20. São Paulo: Galeria Sinduscon, I995.

ELUF, Lygia (org.). Anita Malfatti - Coleção Cadernos de Desenho. Campinas: Editora Unicamp/Imprensa Oficial do Estado de São Paulo, 20 II.

PINTO, S. M. de Carvalho. A controversa pintura de Anita Malfatti. Tese (Doutorado). São Paulo: Universidade de São Paulo, 2007. 